\title{
Deposition of Gold (III) from Hydrochloric Acid Solutions on Carbon Nanotubes under Hydrothermal Conditions
}

\author{
Roman V. Borisov*a,b, \\ Oleg V. Belousov ${ }^{\mathrm{a}, \mathrm{b}}$ and Anatoliy M. Zhizhaev ${ }^{\mathrm{a}}$ \\ anstitute of Chemistry and Chemical Technology SB RAS \\ FRC "Krasnoyarsk Science Center SB RAS" \\ 50/24 Akademgorodok, Krasnoyarsk, 660036, Russia \\ ${ }^{b}$ Siberian Federal University \\ 79 Svobodny, Krasnoyarsk, 660041, Russia
}

Received 03.06.20189, received in revised form 27.08.2019, accepted 09.10.2019

The paper deals with the recovery of gold (III) from hydrochloric acid solutions on carbon based nanotube material at elevated temperatures under autoclave conditions. It is established that the quantitative recovery of gold (III) from hydrochloric acid solution upon its contact with carbon material occurs at a temperature of $170{ }^{\circ} \mathrm{C}$ for 240 minutes. The morphological features of metallic gold particles are studies by scanning electron microscopy.

Keywords: hydrothermal conditions, gold, carbon nanotubes, electron microscopy.

Citation: Borisov R.V., Belousov O.V., Zhizhaev A.M. Deposition of gold (III) from hydrochloric acid solutions on carbon nanotubes under hydrothermal conditions, J. Sib. Fed. Univ. Chem., 2019, 12(4), 494-502. DOI: 10.17516/1998-2836-0145.

(C) Siberian Federal University. All rights reserved

* Corresponding author E-mail address: roma_boris@list.ru 


\title{
Осаждение золота (III) из солянокислых растворов \\ на углеродные нанотрубки \\ в гидротермальных условиях
}

\author{
Р.В. Борисов ${ }^{\mathrm{a}, \tilde{\sigma}}$, О.В. Белоусов ${ }^{\mathrm{a}, \tilde{0}}$, А.М. Жижаев ${ }^{\mathrm{a}}$ \\ ${ }^{a}$ Институт химии и химической технологии СО РАН \\ ФИЦ «Красноярский научный центр СО РАН» \\ Россия, 660036, Красноярск, Академгородок, 50/24 \\ ${ }^{6}$ Сибирский федеральный университет \\ Россия, 660041, Красноярск, пр. Свободный, 79
}

В работе рассмотрены вопросы восстановления золота (III) из солянокислых растворов на углеродном материале на основе нанотрубок при повыменных температурах в автоклавных условиях. Выявлено, что количественное восстановление золота (III) из солянокислого раствора при его контакте с углеродным материалом происходит при температуре $170{ }^{\circ} \mathrm{C}$ в течение 240 мин. Сканирующей электронной микроскопией исследованы морфологические особенности образуюшихся частии.

Ключевые слова: гидротермальные условия, золото, нанотрубки, электронная микроскопия.

\section{Введение}

Процессы осаждения золота на различных углеродных материалах представляют интерес, с одной стороны, в области создания новых функциональных композитных материалов [1-3], а с другой - в технологиях извлечения и аффинажа золота [4-6], а также понимания геохимических процессов миграции и осаждения золота на углистых веществах в гидротермальных условиях [7]. Достаточно актуально создание новых материалов, состоящих из углеродных нанотрубок с нанесенными наночастицами благородного металла. Данные материалы находят широкое применение в катализе, наноэлектронике, биосенсорах ввиду уникальных свойств, обусловленных сочетанием углеродной матрицы и благородного металла. В работах $[1,2]$ рассмотрены методы синтеза таких функциональных материалов в открытых системах. Например, можно использовать восстановление водных растворов золота (III) цитратом натрия с помощью ультразвука. В работах [8-11] изложены гидротермальные подходы формирования металлических частиц благородных металлов, которые могут быть использованы в качестве катализаторов, например, гидрирования.

С другой стороны, процессы сорбции и восстановления на углеродных материалах применяются для извлечения ионов золота из растворов, например, в процессе цианирования золотосодержащего сырья по технологии «уголь в пульпе» [4, 5], доизвлечения ценных компонентов из растворов с крайне низким содержанием благородных металлов. В работе [3] рассмотрены процессы синтеза достаточно крупных частиц золота размером до 120 нм на углеродной матрице. Данные образцы показали высокую активность для улавливания ртути.

В последнее время в качестве носителей металлических частиц активно используются углеродные нанотрубки и материалы на их основе, которые проявляют уникальные физические, хи- 
мические, электронные и механические свойства [11]. В работе [11] изучены процессы сорбции на углеродных нанотрубках золота (III) на фоне других ионов переходных металлов из кислых сред при комнатных температурах. В случае предварительного окисления нанотрубок азотной кислотой авторами [12] обнаружена высокая скорость и селективность сорбции ионов золота (III).

Цель настоящей работы - изучить особенности образования металлических фаз золота из солянокислых растворов золотохлористоводородной кислоты на углеродном материале на основе нанотрубок при повышенных температурах в автоклавных условиях.

\section{Экспериментальная часть}

В данной работе использовали: золотохлористоводородную кислоту кристаллогидрат (массовая доля золота 47,47 \%) производства ОАО «Красцветмет»; соляную кислоту - «ос.ч.», аргон газообразный - сорт высший. Рабочие растворы готовили разбавлением рассчитанных аликвот реагентов деионизированной водой, полученной на системе очистки воды Direct_Q3 (Millipore).

В качестве носителя брали коммерческий углеродный материал на основе нанотрубок, представляющий собой нитевидные образования графита длиной более 2 мкм с наружными диаметрами от 20 до 40 нм в виде сыпучего порошка черного цвета [13].

Эксперименты проводили в кварцевых автоклавах объемом $45 \mathrm{~cm}^{3}$ по методике, описанной в работах $[14,15]$.

Навеску углеродного материала 0,300 г помещали во фторопластовую чашечку, размещенную на внутренней поверхности крышки автоклава. В кварцевый автоклав заливали $30 \mathrm{~cm}^{3}$ раствора $\mathrm{HAuCl}_{4}$ требуемой концентрации. В камере удаляли воздух, пропуская аргон через раствор в течение 60 мин, герметизировали реактор. Автоклав помещали в термостат, прогретый до рабочей температуры (110 или $\left.170{ }^{\circ} \mathrm{C}\right)$. После прогрева до необходимой температуры включали перемешивание, тем самым обеспечивая смешение твердой фазы и раствора только при требуемой температуре. После термостатирования в течение заданного времени (15-480 мин) автоклав охлаждали. Аликвоту раствора отбирали для определения концентрации золота на атомно-адсорбционном спектрометре AAnalyst-400 (Perkin Elmer, США). Осадок многократно промывали деионизированной водой до отрицательной реакции на хлорид-ион и сушили при температуре $100{ }^{\circ} \mathrm{C}$.

Регистрация изотерм адсорбции азота была выполнена с помощью анализатора ASAP-2420 (Micromeritics, USA) при 77 К. Расчет текстурных характеристик осуществляли с помощью методов ВЈН и ВЕТ. Исследования морфологических особенностей осажденных частиц проводили методом сканирующей электронной микроскопии на приборах TM3000 (Hitachi, Япония) с системой микроанализа Quantax 70 (Bruker, Германия) и S5500 (Hitachi, Япония). Рентгеновские дифрактограммы регистрировали в диапазоне углов $2 \Theta$ от 5 до $90^{\circ}$ с шагом $0,02^{\circ}$ на настольном дифрактометре Proto AiXRD (Proto Manufacturing, Канада) с использованием $\mathrm{Cu} \mathrm{K \alpha}$ излучения с накоплением в точке 3 c.

\section{Результаты и их обсуждение}

Углеродный материал на основе нанотрубок обладает следующими текстурными характеристиками: удельная поверхность $152 \mathrm{~m}^{2} / \Gamma$, объем пор $0,27 \mathrm{~cm}^{3} / \Gamma$, средний диаметр пор 7 нм. Гид- 
ротермальная обработка материала при температуре $180^{\circ} \mathrm{C}$ в $1 \mathrm{M}$ соляной кислоте не приводит к существенному изменению текстурных характеристик. Методом сканирующей электронной микроскопии высокого разрешения с микрорентгеноспектральным анализом на углеродных нанотрубках примесных включений не обнаружено.

Золото (III) в растворах может легко восстанавливаться до металлического состояния под воздействием облучения (ультрафиолет) [16, 17], различных химических восстановителей, при контакте с минералами (например, сульфидными [18]) и углеродными материалами [12, 16, 19$]$. Образование металлических частиц золота на углеродных материалах может быть связано с процессами сорбции и восстановления золота (III) из солянокислых растворов $[12,19]$. Возможные механизмы сорбции золота (III) детально рассмотрены в работе [16].

В табл. 1 приведены условия и результаты экспериментов. Установлено, что при контакте углеродных нанотрубок с солянокислыми растворами золотохлористоводородной кислоты в закрытой системе в гидротермальных условиях происходит снижение концентрации золота (III) в растворе. На рис. 1 показаны кинетические зависимости изменения концентрации золота (III) в растворе $\left(\mathrm{C}_{\mathrm{Au}}{ }^{3+}\right.$ исх $\left.197 \mathrm{Mг} / л\right)$ при 170 и $110{ }^{\circ} \mathrm{C}$. Уже после 240 мин контакта при температуре $110{ }^{\circ} \mathrm{C}$ концентрация золота в растворе составила 108 мг/л, т.е. уменьшалась почти в 2 раза. Данный процесс может быть обусловлен процессами сорбции и последующим восстановлением золота на углеродном носителе.

Действительно, по результатам электронно-микроскопического анализа (рис. 2) на углеродных нанотрубках обнаружены металлические частицы золота (0).

На рис. $2 A$ показаны многочисленные частицы золота (0), покрывающие углеродные волокна, которые образовались после 60 мин контакта (обр. № 10, табл. 1) при температуре $110{ }^{\circ} \mathrm{C}$. Уменьшение концентрации золота (III) в этом случае составило 26 \%. Частицы золота имеют размеры менее 100 нм и округлую форму. Увеличение времени контакта до 240 мин приводит

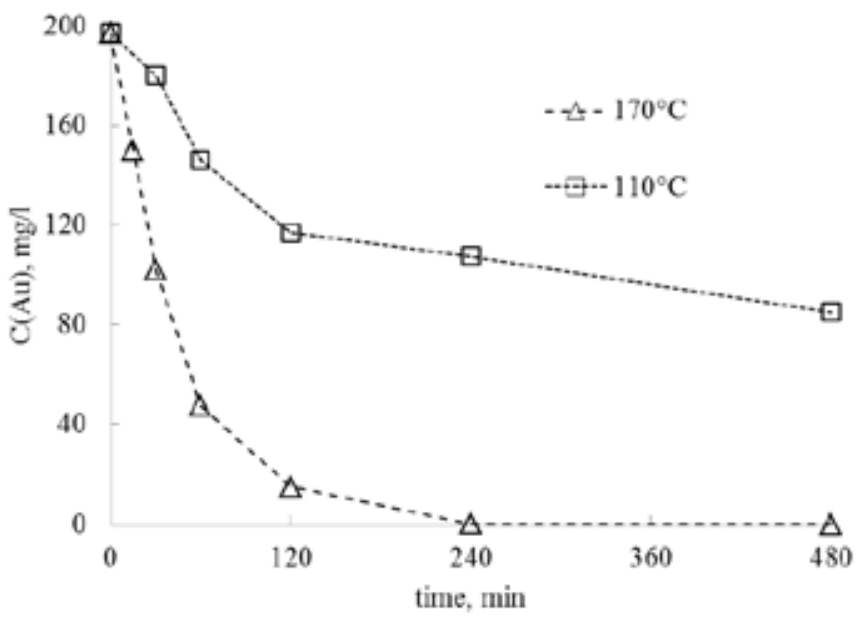

Рис. 1. Изменение концентрации золота(ІІІ) в растворе при различной продолжительности контакта с углеродным материалом при температурах 110 и $170{ }^{\circ} \mathrm{C}$

Fig. 1. Changes in the concentration of gold (III) in solution at different durations of contact with carbon material at temperatures of 110 and $170{ }^{\circ} \mathrm{C}$ 

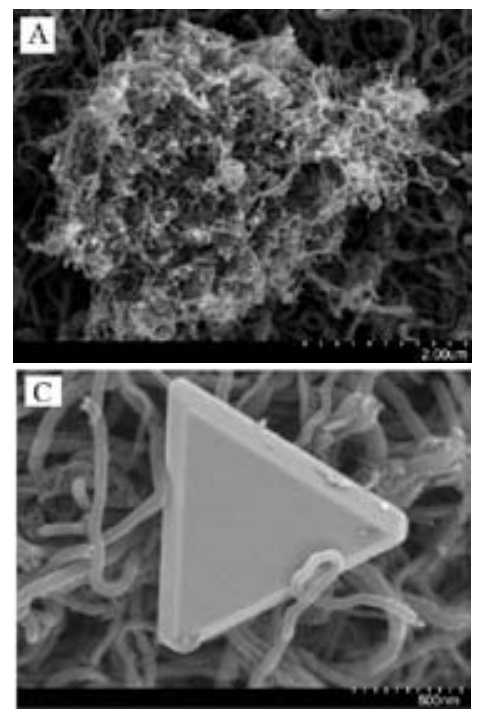
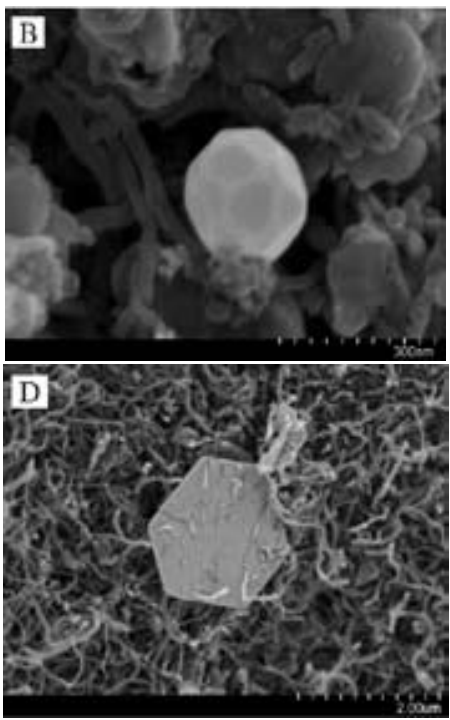

Рис. 2. СЭМ-изображения частиц золота (0), образующихся на углеродном материале на основе нанотрубок при температуре $110^{\circ} \mathrm{C}$ в течение: А - 60 мин; B, C, D - 240 мин

Fig. 2. SEM images of gold particles ( 0 ) formed on carbon based nanotube material at a temperature of $110{ }^{\circ} \mathrm{C}$ for: A - 60 minutes; B, C, D - 240 minutes

к образованию частиц золота размером от 0,2 до 1,5 мкм. Наряду с частицами неправильной формы обнаружены симметричные кристаллы золота: плоские треугольники, шестиугольники, додекаэдры. В работе [20] отмечено, что золото склонно к образованию нанокристаллов правильной формы, например плоских треугольников с ребром около 1 мкм.

Увеличение температуры экспериментов до $170{ }^{\circ} \mathrm{C}$ приводит к уменьшению концентрации золота (III) в растворе со 197 до 15 мг/л за 120 мин (табл. 1, обр. № 4), а после 240 мин концентрация становится ниже предела обнаружения ( $<0,1$ мг/л). В твердой фазе, полученной после контакта при температуре $170{ }^{\circ} \mathrm{C}$, обнаружить симметричные частицы, как при $110{ }^{\circ} \mathrm{C}$, не удалось даже в результате многочисленных электронно-микроскопических исследований образцов № 4, 5, 6 (табл. 1).

При продолжительности эксперимента 60 мин на углеродных нанотрубках обнаружены частицы размером до 1 мкм, состоящие из многочисленных «оплавленных» частиц сферической формы размером до 0,2 мкм (рис. $3 A, B$ ). Увеличение продолжительности экспериментов приводит к росту металлических частиц золота, однако их морфологические особенности не меняются (рис. $3 C, D$ ).

Десятикратное увеличение исходной концентрации золота (III) в растворах (1970 мг/л) приводит к некоторому уменьшению степени его восстановления. Так, при контакте в течение 240 мин при $170{ }^{\circ} \mathrm{C}$ остаточная концентрация золота (III) в растворе составила $400 \mathrm{мг/л,} \mathrm{доля}$ золота (0) на углеродных нанотрубках - более $13 \%$.

Рентгенофазовый анализ синтезированных материалов (рис. 4) показал наличие наборов пиков, соответствующих золоту (0). Значимых уширений пиков золота не наблюдается, что говорит об отсутствии дисперсных частиц и согласуется с электронно-микроскопическими 
Таблица 1. Параметры автоклавных экспериментов

Table 1. Parameters of autoclave experiments

\begin{tabular}{|c|c|c|c|c|c|}
\hline № оп & $\mathrm{C}\left(\mathrm{Au}^{3+}\right)$, мг/л & $\mathrm{T},{ }^{\circ} \mathrm{C}$ & Время, мин & $\begin{array}{c}\text { Уменьшение } \\
\mathrm{C}\left(\mathrm{Au}^{3+}\right) \text { в } \\
\text { растворе, \% }\end{array}$ & $\begin{array}{c}\mathrm{Au}^{0} \text { на } \\
\text { углероде, \% } \\
\text { масс. }\end{array}$ \\
\hline 1 & \multirow{6}{*}{197} & \multirow{6}{*}{170} & 15 & 24 & 0,5 \\
\hline 2 & & & 30 & 48 & 0,9 \\
\hline 3 & & & 60 & 76 & 1,5 \\
\hline 4 & & & 120 & 92 & 1,8 \\
\hline 5 & & & 240 & 100 & 1,9 \\
\hline 6 & & & 480 & 100 & 1,9 \\
\hline 7 & 1970 & 170 & 240 & 80 & 13,4 \\
\hline 8* & 197 & 170 & 240 & 64 & 1,2 \\
\hline 9 & \multirow{5}{*}{197} & \multirow{5}{*}{110} & 30 & 9 & 0,2 \\
\hline 10 & & & 60 & 26 & 0,5 \\
\hline 11 & & & 120 & 41 & 0,8 \\
\hline 12 & & & 240 & 45 & 0,9 \\
\hline 13 & & & 480 & 57 & 1,1 \\
\hline 14 & 1970 & 110 & 240 & 32 & 6,0 \\
\hline
\end{tabular}

* - опыт проведен в атмосфере воздуха.
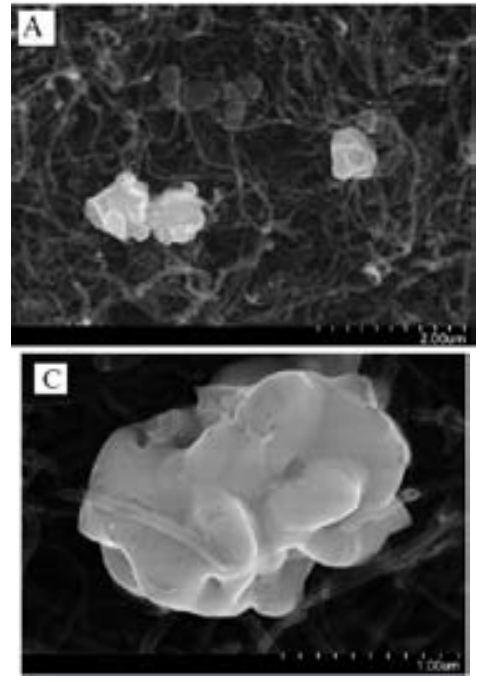
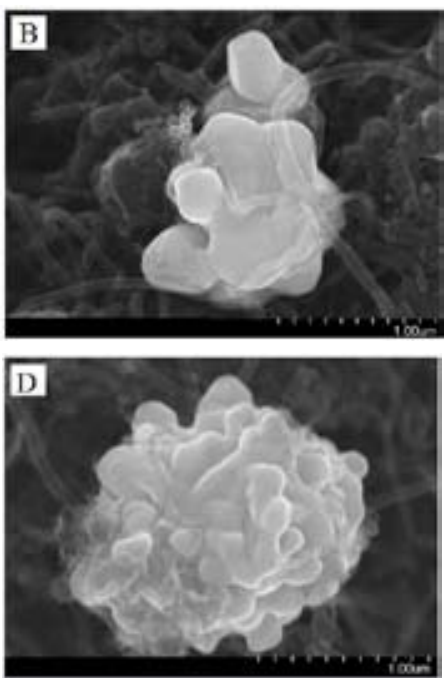

Рис. 3. СЭМ-изображения частиц золота (0), образующихся на углеродном материале на основе нанотрубок при температуре $170{ }^{\circ} \mathrm{C}$ в течение: А, В - 60 мин; C, D - 240 мин

Fig. 3. SEM images of gold particles (0) formed on carbon based nanotube material at a temperature of $170{ }^{\circ} \mathrm{C}$ for: A, B - 60 minutes; C, D - 240 minutes

исследованиями. На рис. 4 приведены рентгенограммы образцов № 5 и № 14 (табл. 1). Пик в районе $26^{\circ}$ соответствует углеродному материалу и может быть идентифицирован как поликристаллический графит, размытый пик районе 43-44을 перекрывающийся с пиком золота

$$
-499-
$$




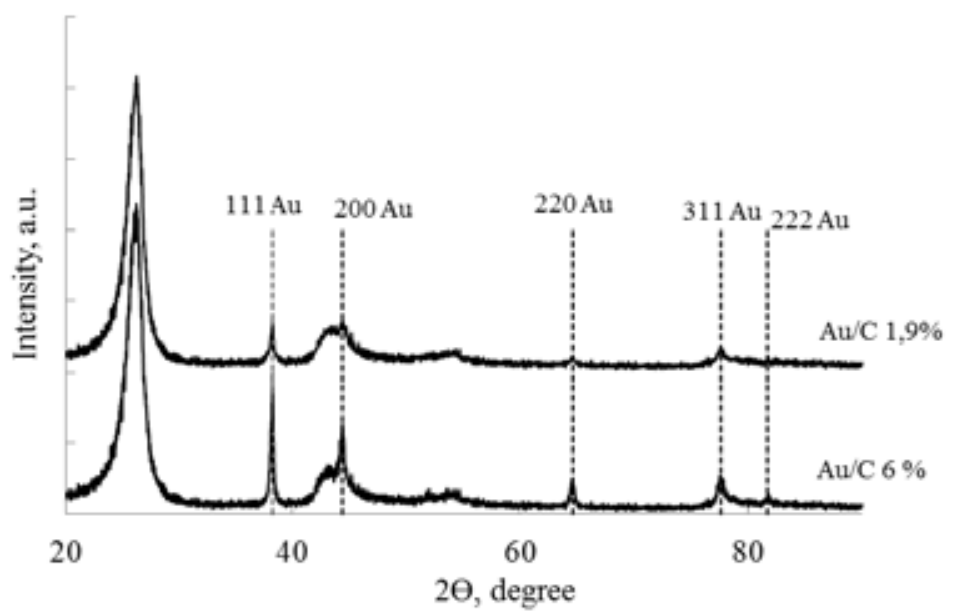

Рис. 4. Дифрактограммы продуктов осаждения золота(III) на углеродный материал на основе нанотрубок: образец № 5 и образец № 14 (табл. 1)

Fig. 4. XRD patterns of the products of gold (III) deposition on carbon material based on nanotubes: sample No. 5 and sample No. 14 (Table 1)

(200), соответствует поликристаллическим примесям в материале нанотрубок [13]. Пики золота (0) на нанотрубках при содержании менее 2 \% масс. на фоне углеродного носителя выражены крайне слабо.

При проведении экспериментов без замещения воздуха в автоклаве инертным газом наблюдалось снижение степени восстановления золота (III) (№ 8, табл. 1). Вероятно, в данном случае могут происходить процессы окисления свежеобразованных частиц золота кислородом воздуха.

Таким образом, в результате контакта солянокислого раствора $\mathrm{HAuCl}_{4}$ с углеродным носителем при повышенных температурах в закрытых системах происходит уменьшение концентрации золота (III). Данный процесс сопровождается формированием на нанотрубках металлических частиц золота (0) различной формы и размеров, что подтверждено рентгенофазовым анализом и сканирующей электронной микроскопией с рентгеноспектральным микроанализом. Установлено, что при температуре $110^{\circ} \mathrm{C}$ происходит формирование как многочисленных частиц размерами менее 0,1 мкм, так и преимущественно симметричных кристаллов золота размером около 1 мкм. При $170{ }^{\circ} \mathrm{C}$ процесс образования металлических частиц золота (0) протекает значительно быстрее, симметричные частицы в данном случае не обнаружены.

\section{Благодарности}

Инструментальные исследования выполнены с использованием оборудования Красноярского регионального центра коллективного пользования СО РАН.

Работа выполнена за счет средств Федерального бюджета на реализацию проекта № V.46.1.2. 


\section{Список литературы}

1. Zhang R., Hummelgård M., Olin H. Simple and efficient gold nanoparticles deposition on carbon nanotubes with controllable particle sizes. Materials Science and Engineering: B 2001. Vol. 158 (1-3), P. 48-52.

2. Seifi M., Abdolrahimi M. Synthesis and comparative study of optical and electrical properties of Au-doped carbon nanotubes prepared in different reaction media. Chinese journal of physics 2018. Vol. 56 (2), P. 476-483.

3. Gómez-Giménez C., Ballestero D., Ferrer N., Rubio B., Izquierdo M. T. Influence of crystal/ particle size and gold content of a structured $\mathrm{Au} / \mathrm{C}$ based sorbent on mercury capture. Journal of Physics and Chemistry of Solids 2017. Vol.110, P. 173-179.

4. Snyders C.A., Mpinga C.N., Bradshaw S.M., Akdogan G., Eksteen J.J. The application of activated carbon for the adsorption and elution of platinum group metals from dilute cyanide leach solutions. Journal of the Southern African Institute of Mining and Metallurgy 2013. Vol. 113(5), P. 381-388.

5. Fleming C.A., Mezei A., Bourricaudy E., Canizares M., Ashbury M. Factors influencing the rate of gold cyanide leaching and adsorption on activated carbon, and their impact on the design of CIL and CIP circuits. Minerals Engineering 2011. Vol. 24(6), P. 484-494.

6. Vorob'ev-Desyatovskii N.V., Kubyshkin S.A., Ibragimova R.I., Kaichev V.V., Dubrovskii Y.A., Babakov V.N., Pichugina D.A. Study of sorption of platinum and palladium cyanometallate complexes as the key to understanding the mechanism of binding the $\left[\mathrm{Au}(\mathrm{CN})_{2}\right]^{-}$anion with carbon adsorbents. Russian Journal of General Chemistry 2012. Vol. 82(3), P. 384-397.

7. Kerr G., Craw D. Mineralogy and geochemistry of biologically-mediated gold mobilisation and redeposition in a semiarid climate, southern New Zealand. Minerals 2017. Vol. 7(8), P. 147.

8. Fesik E.V., Buslaeva T.M., Mel'nikova T.I., Tarasova L.S. Solid-State Thermal Transformations in a Mixture of Palladium Tetraammine Dichloride with Ammonium Chromate. Inorganic Materials 2018. Vol. 54(12), P. 1299-1307.

9. Belousov O.V., Tarabanko V.E., Borisov R.V., Simakova I.L., Zhyzhaev A.M., Tarabanko N., Isakova V.G., Parfenov V.A., Ponomarenko I.V. Synthesis and catalytic hydrogenation activity of Pd and bimetallic Au-Pd nanoparticles supported on high-porosity carbon materials. Reaction Kinetics, Mechanisms and Catalysis 2019. Vol. 127(1), P. 25-39.

10. Fesik E.V., Buslaeva T.M., Melnikova T.I. Synthesis of Bimetallic Pt-W Particles in Autoclave. Russian Journal of General Chemistry 2019. Vol. 89(2), P. 309-312.

11. Ravelo-Pérez L.M., Herrera-Herrera A.V., Hernández-Borges J., Rodríguez-Delgado M.Á. Carbon nanotubes: solid-phase extraction. Journal of Chromatography A 2010. Vol. 1217(16), P. 2618-2641.

12. Shaheen H.A., Marwani H.M., Soliman E.M. Selective adsorption of gold ions from complex system using oxidized multi-walled carbon nanotubes. Journal of Molecular Liquids 2015. Vol. 212, P. 480-486.

13. Ткачев А.Г. УГлеродный наноматериал Таунит - структура, свойства, производство и применение. Перспективные материалы 2007. T. 3, C.5-9. [Tkachev A.G. Carbon nanomaterial Taunit structure, properties, production and use. Perspective materials 2007. V. 3, P.5-9. (In Russ.)] 
14. Borisov R.V., Belousov O.V., Zhizhaev A.M., Belousova N.V., Kirik S.D. Carbon-Supported Palladium-Gold Bimetallic Disperse Systems Formed in Aqueous Solutions at 110 degrees. Russian Journal of Inorganic Chemistry 2018. Vol. 63(3), P. 308-313.

15. Борисов Р.В., Белоусов О.В. Формирование нанокристаллических фаз палладия и платины на углеродных носителях в автоклавных условиях. Журнал Сибирского федерального университета. Химия 2014. T. 7(3), C.331-339. [Borisov R.V., Belousov O.V. The formation of nanocrystalline phases of palladium and platinum on carbon substrates under autoclave conditions. Journal of the Siberian Federal University. Chemistry 2014. Vol. 7 (3), P. 311-339. (In Russ.)]

16. Смолкина Т. В., Буйновский А.С., Колпакова Н.А., Молоков П.Б., Левченко Л.М. Определение механизма концентрирования золота из растворов на углях марки БАУ под воздействием ультрафиолетового облучения. Химия в интересах устойчивого развития 2011. Т. 19, С. 195-202. [Smolkina T.V., Buynovskiy A.S., Kolpakova N.A., Molokov P.B., Levchenko L.M. Determination of the mechanism for the concentration of gold from solutions on charcoal of the BAU grade under the influence of ultraviolet irradiation. Chemistry in the interests of sustainable development 2011. Vol. 19, P. 195-202. (In Russ.)]

17. Daniel M. C., Astruc, D. Gold nanoparticles: assembly, supramolecular chemistry, quantumsize-related properties, and applications toward biology, catalysis, and nanotechnology, Chemical reviews 2004. Vol. 104(1), P. 293-346.

18. Shuster J., Reith F., Cornelis G., Parsons J. E., Parsons J. M., Southam G. Chemical Geology 2017. Vol. 450, P. 154-164.

19. Симанова С.А., Щукарев А.В., Лысенко А.А., Гребенников С.Ф., Асташкина О.В. Адсорбция хлорокомплексов палладия, платины и золота углеродными волокнами различной структуры. Химические волокна 2008. Vol. 4, P.61-69. [Simanova S.A., Shchukarev A.V., Lysenko A.A., Grebennikov S.F., Astashkina O.V. Adsorption of chlorine complexes of palladium, platinum and gold by carbon fibers of various structures. Chemical Fibers 2008, Vol. 4, P. 61-69. (In Russ.)]

20. Shankar S.S., Rai A., Ankamwar B., Singh A., Ahmad A., Sastry M. Biological synthesis of triangular gold nanoprisms. Nature materials 2004. Vol. 3(7), P. 482-488. 